\title{
Behavioral Study of RC Beams Designed for Shear Using CFP and ACI Code Models
}

\author{
Tehmina Ayub ${ }^{1, *}$, Sadaqat Ullah Khan ${ }^{2}$, and Wajeeha Mahmood ${ }^{1}$ \\ ${ }^{1}$ Department of Civil Engineering, NED University of Engineering and Technology, Karachi 75270, \\ Pakistan \\ 2 Department of Urban and Infrastructure Engineering, NED University of Engineering and \\ Technology, Karachi 75270, Pakistan
}

\begin{abstract}
Compressive Force Path concept is a proposed shear design method to explain shear behavior in reinforced concrete beams. This concept identifies 04 behaviors based on the shear span to beam depth (a/d) ratio and provides detailed shear design and transverse reinforcement detailing procedure for each behavior. Therefore, author of this paper intended to use this concept as a practical tool for the designing of RC beams particularly for Type II $(2 \leq a / d<5)$ and Type III $(1<$ a/d $<2)$ behaviors to validate the concept. Total 08 beams of $100 \times 200 \times 1800 \mathrm{~mm}$ size beams were cast; out of which, 04 beams were designed according to ACI Code approach while, rest were designed and detailed using CFP concept strategy. The beam sizes in this study are identical and all parameters are constant except shear span ' $a$ '. The two-point loading test results of RC beams showed that the shear resistance of concrete is better estimated by the CFP concept with a good prediction of cracks pattern, load carrying capacity and actual behavior of the beams in shear as compared to the beams designed according to ACI Code approach. However, most of the beams, particularly a/d ratio less than 4.44 were observed to be deficient in serviceability and failed in shear in spite of attaining theoretical predicted loads.
\end{abstract}

\section{Introduction}

In conventional practice, shear design of RC beams is based on the sectional model as $V_{\mathrm{n}}=V_{\mathrm{c}}+V_{\mathrm{s}}\left(\right.$ Eq. $(11-2)$ of ACI $318 \mathrm{M}-08$ [1]); where, $V_{\mathrm{n}}$ is the nominal shear resistance offered by section, $V_{\mathrm{c}}$ is the shear strength of concrete calculated by Eq. (11-5) of ACI $318 \mathrm{M}-08$ [1] and $V_{\mathrm{s}}$ is the contribution of transverse reinforcement in shear resistance. Eq. (11-5) is statistically arrived and has been criticized occasionally (e.g. Brown [2] and Collin et al. [3], etc.), but it is versatile as it considers all possible parameters on which shear strength of an RC section is generally assumed to be dependent and therefore, it is being used extensively. Among several methods to predict the shear strength of RC beams; a new concept of 'Compressive Force Path (CFP)' was proposed by Kotsovos [4], which is claimed as yielding based design solution with more safety and efficiency than the current

*Corresponding author: tehmina@,neduet.edu.pk 
ACI design method. According to CFP concept, shear resistance of an RC member depends on the strength of concrete in the region of the path through which compressive force is transferred to the supports and shear failure is associated with the development of the excessive tensile stresses in the region (refer to Figure 1). This concept identifies 04 behaviors for an RC beam having a constant cross section and flexure reinforcement, if it is subjected to two-point loading with variable $a / d$ ratio. Type I behavior is characterized with $a / d>5$ where beam eventually attains its full flexure capacity and Type IV behavior is corresponded to $a / d<1$ representing deep beam behavior. The failure of Type II and Type III beam behaviors may be brittle in nature and is expected to occur within shear span. Therefore, Kotsovos and Pavlovic [5] identified shear design and transverse reinforcement detailing rules for these two behaviors of RC beams to achieve theoretical flexural capacity estimated through well-established ACI 318M-08 [1] for a tension controlled section while, there is no detail for the prediction of the failure mode. Therefore, this method does have merit as far as the load prediction is concerned; however, it may or may not essentially predict the failure mode. ACI method, on the other hand, relies on much desired ductile flexural failure. Therefore, the main objective of this paper is to validate the abovementioned contention of the proponent of CFP concept along with the discussion on the failure modes.

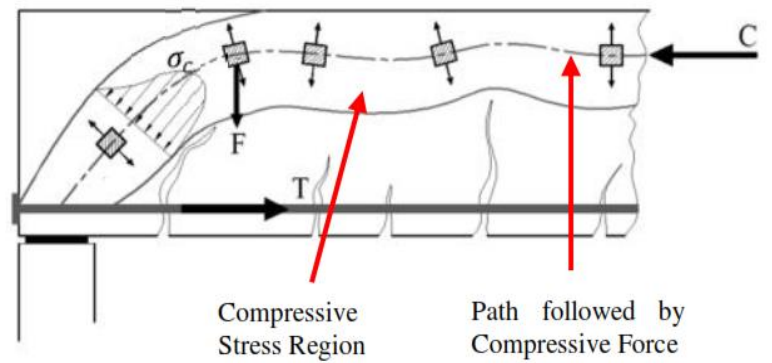

$\sigma_{\mathrm{c}}$ is the compressive stress developed in the region of compressive zone as shown. $\mathrm{F}$ is the tensile stress action which may develop at the location where compressive stress changes its direction as a response of vertical component of the inclined compressive stress resultant and tends to separate this portion of compressive zone from remaining beam by splitting close-horizontally

Fig.1. Location of tensile stresses (Adapted from Kotsovos and Pavlovic, 1999)

\section{Shear Design Procedure and Transverse Reinforcement Detailing for Type II and Type III Behaviors}

For shear designing, physical RC beam is assumed as 'frame' comprising of horizontal element, which is actually a compressive zone of the beam and inclined legs tied by tensile reinforcement as shown in Figure 2 and Figure 3. This 'frame' mainly depends on a/d ratio, which identifies the behavioral characteristic and failure criterion in RC beam. Type II behavior occurs due to the development of tensile stresses in the region where compressive force path changes its direction (refer to Figure 1) known as 'Kink' as shown in Figure 2. The shear resistance of concrete in this region is given by $V_{\mathrm{c}}=M_{\mathrm{c}} / s$; where, $M_{\mathrm{c}}$ is the moment (in unit N-mm) for the section which is under consideration using Eq. (1) as described underneath, and its location is measured from support as ' $s$ ':

$$
M_{c}=0.875 s d\left(0.342 b+0.3 \frac{M_{f}}{d^{2}} \sqrt{\frac{z}{s}}\right) \sqrt[4]{\frac{16.66}{\rho_{w} f_{y}}}
$$

where, ' $s$ ' is equal to the shear span length ' $a$ ' and ' $2 d$ ' for Type II and Type III behaviors. In Eq. (1), ' $d$ ' and ' $b$ ' are the effective depth and width of the beam section, ' $M_{\mathrm{f}}$ ' 
is the maximum flexural capacity prior to the cross sectional failure, ' $z$ ' is the lever arm measured from the center of compressive stress block (assuming rectangular stress block shown in Figure 4) to the center of flexure reinforcement, ' $\rho_{w}$ ' is the ratio of area of flexural reinforcement to the area of effective cross section $\left(A_{\mathrm{s}} / b_{\mathrm{w}} d\right)$ for the rectangular cross section and $f_{\mathrm{y}}$ is the yield strength of flexural reinforcement. As failure of Type II beam involves the near horizontal splitting of the beam in the region where path of the resultant compressive stress changes its direction i.e. 'Kink' (refer to Figure 2). Therefore, stirrups are required to sustain the portion of external shear force ' $V_{\mathrm{a}}$ ' in excess of ' $V_{\mathrm{c}}$ ' called as transverse force ' $T$ sv' to prevent brittle failure of 'Kink'. The required shear reinforcement area is

$$
A_{s v}=\frac{T_{s v}}{f_{y v}}
$$

where, ' $f$ yv' is the yield strength of shear reinforcement which has to be uniformly distributed over a distance ' $d / 2$ ' at both sides of the Kink, which exists at a distance of $2 \mathrm{~d}$ from the support (refer to Figure 2). In the remaining part of the beam, minimum shear reinforcement is sufficient to sustain the tensile stresses of order of $0.5 \mathrm{MPa}$ suggested by the proponent of CFP concept. For Type III beams, brittle failure is associated with the failure of horizontal member of the frame; therefore, stirrups should be provided throughout between support and Kink as shown in Figure 3, to increase the load carrying capacity of the section with increasing suppression of shear stresses.

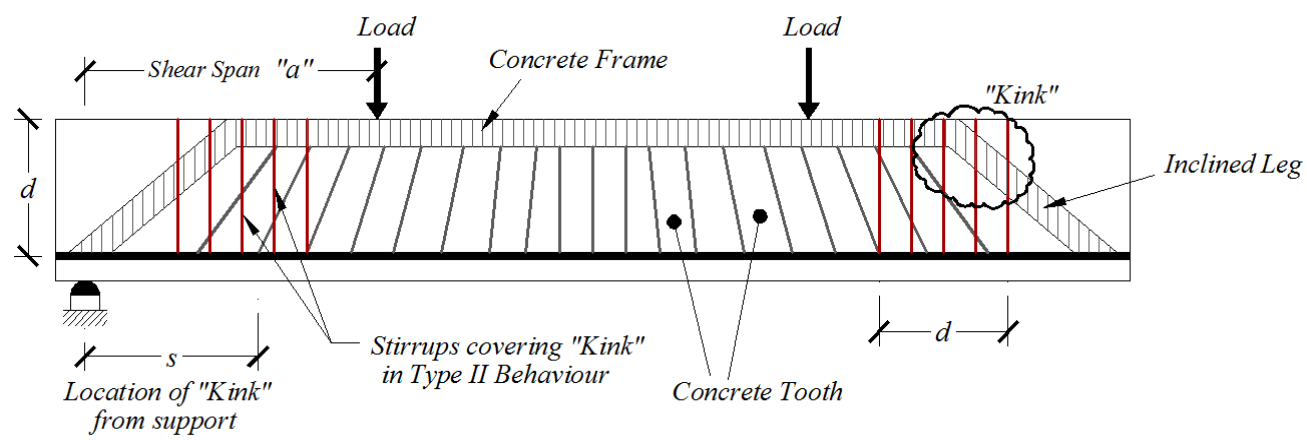

Fig.2. Proposed transverse reinforcement in Type II beam (Kotsovos and Pavlovic, 1999)

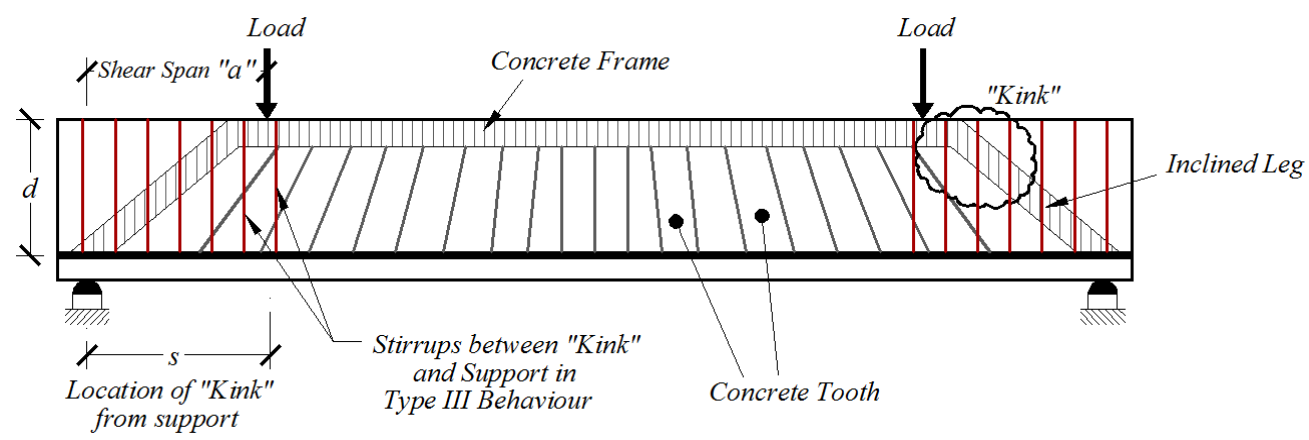

Fig.3. Proposed transverse reinforcement in Type III beam (Kotsovos and Pavlovic, 1999) 


\section{EXPERIMENTAL Program}

The experimental program was designed for the beams of Type II and Type III behaviors shown in ' $\mathrm{V}$ ' portions of the curve shown in Figure 5, showing famous Kani's Valley presented by Kani [6]. Total $04 a / d$ ratios were selected (refer to Figure 5), 03 on the right side of the curve for Type II behavior and 01 on the left side of the curve for Type III behavior. Thus, $08 \mathrm{RC}$ beams were detailed for shear $(04$ beams according to ACI code $318 \mathrm{M}-08$ [1] provisions and 04 according to CFP concept). The reinforcement detailing of all RC beams is shown in Figure 6. All beams were normal strength concrete of $21 \mathrm{MPa}$.

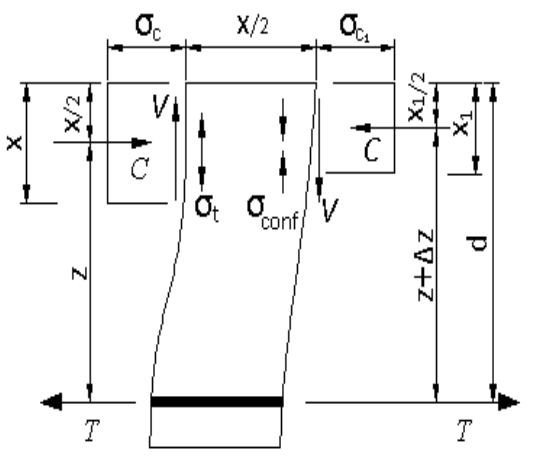

Fig.4. Typical state of stress in between two cracks after bond loss

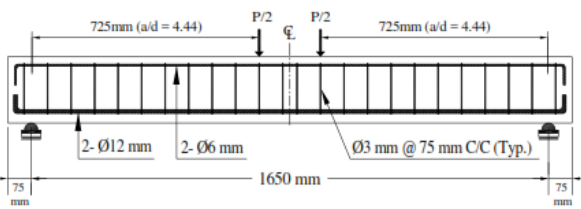

Beam K-4.44 (as per CFP concept)

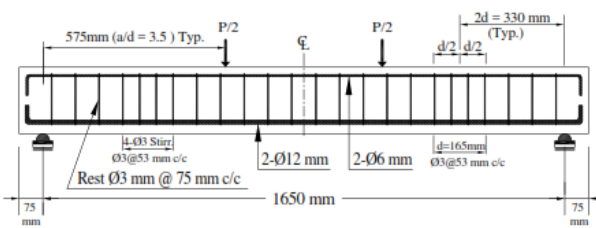

Beam K-3.5 (as per CFP concept)

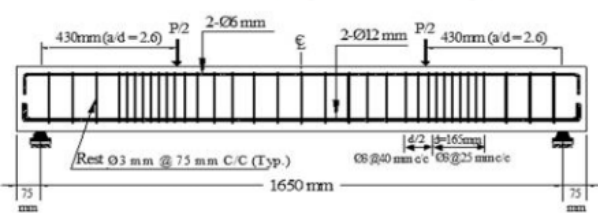

Beam K-2.6 (as per CFP concept)

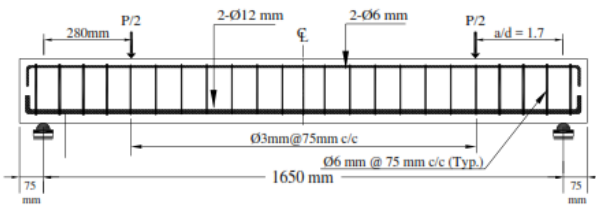

Beam K-1.7 (as per CFP concept)

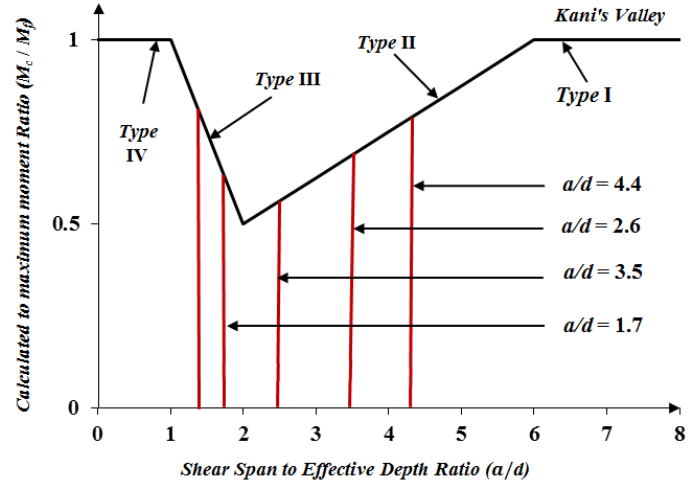

Fig.5. Values of ad ratios selected for the test program

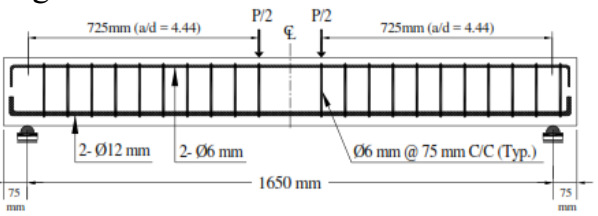

Beam A-4.44 (as per ACI Design)

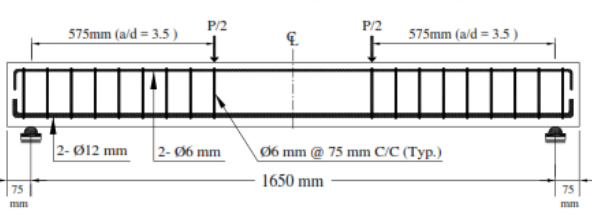

Beam A-3.5 (as per ACI Design)

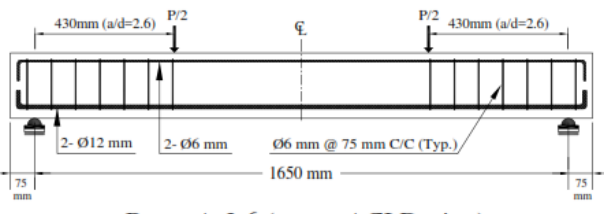

Beam A-2.6 (as per ACI Design)

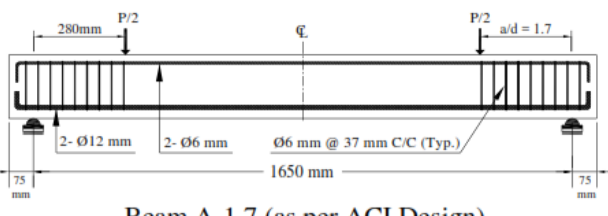

Beam A-1.7 (as per ACI Design)

Fig.6. Beams reinforcement details 


\subsection{Testing procedure and loading arrangement}

All beams were tested to failure at the structural engineering laboratory of NED University of Engineering and Technology, under two-point loading shown in Figure 6.

\subsection{Load carrying capacity, failure modes and cracks}

The failure loads for all beams are given in Table 1 while, failure modes and crack patterns are shown in Figure 7. For the beams with a/d ratio greater than 2, all beams achieved theoretical predicted failure load calculated by Rafeeqi and Ayub (2013) prior to the failure. During testing, the cracks in beams designed according to CFP concept were observed wider than the hairline at service and failed in shear; however, all beams detailed for shear according to ACI provisions failed in flexure mode of failure. For a/d ratio of 4.44 , beam K-4.44 attained $11.87 \%$ higher load than beam A-4.44 using almost $73 \%$ less transverse reinforcement and failed in flexure. This proves better performance of CFP concept; however, beams designed according to ACI code provisions for a/d ratios of 3.5, 2.6 and 1.7 attained higher load and failed in flexure but with higher her amount of shear reinforcement. Whereas, beams designed according to CFP concept attained predicted failure load despite the shear failure using lesser shear reinforcement (refer to Table 1). This concludes that the detailing model of CFP concept seems to perform better for a/d ratio greater than 3.5 with regard to the desired flexural failure and accomplishment of predicted load along with lesser amount of shear reinforcement. However, this model seems inappropriate to achieve desired flexural failure as $a / d$ ratio decreases and therefore, this

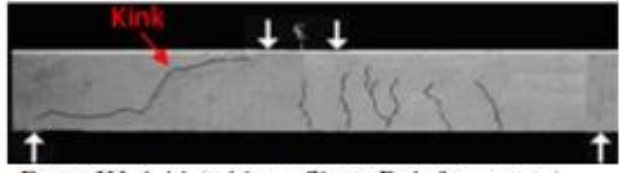

Beam K'-4.44 (without Shear Reinforcement)

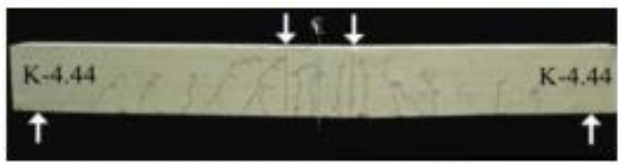

Beam K-4.44 (as per CFP concept)

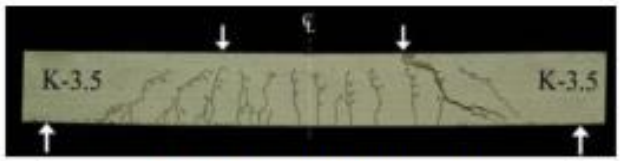

Beam K-3.5 (as per CFP concept)

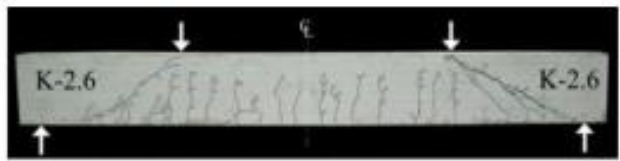

Beam K-2.6 (as per CFP concept)

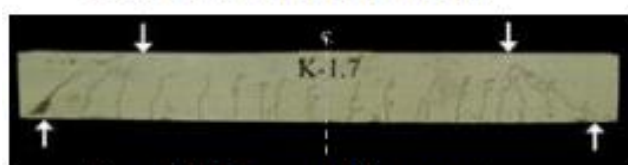

Beam K-1.7 (as per CFP concept)

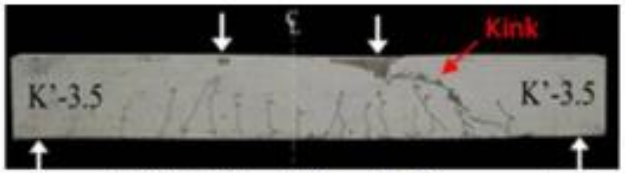

Beam K'-3.5 (without Shear Reinforcement)

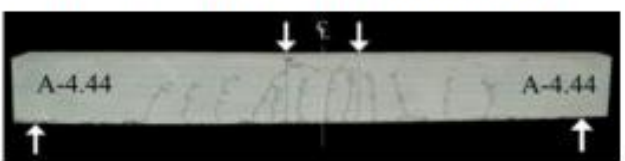

Beam A-4.44 (as per ACI Design)

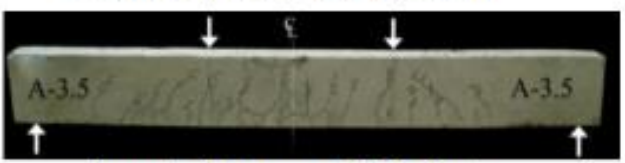

Beam A-3.5 (as per ACI Design)

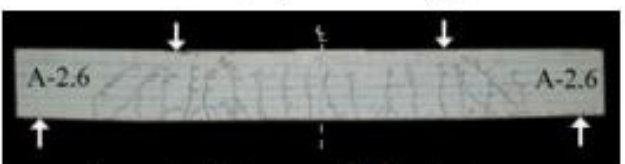

Beam A-2.6 (as per ACI Design)

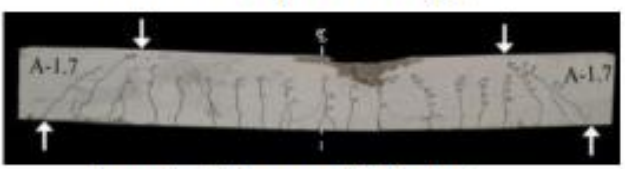

Beam A-1.7 (as per ACI Design)

Fig.7. Crack patterns and mode of failure of the beams 
designing procedure and detailing model may not be appreciated by the practicing engineers in spite of considerable economy in terms of shear reinforcement and attainment of load. Moreover, the load carrying capacity for the beams designed and detailed according to CFP concept decreases as compare to the beams designed and detailed according to ACI code provisions (refer to Table 1), which may be another demerit of CFP concept for a/d ratio less than 3.5. Although, the desired flexural failure is not attained for beams having a/d ratio $=3.5$ but, all beams attained theoretical predicted load and approximately carried 55\% less shear reinforcement.

Table 1. Theoretical loads and variation in failure loads and area of shear reinforcement

\begin{tabular}{|c|c|c|c|c|c|c|c|c|}
\hline \multirow{2}{*}{$\begin{array}{c}\text { a/d } \\
\text { ratio }\end{array}$} & \multicolumn{2}{|c|}{$\begin{array}{l}\text { Theoretical } \\
\text { failure load } \\
\text { (kN) }\end{array}$} & \multicolumn{2}{|c|}{$\begin{array}{l}\text { Experimental } \\
\text { failure load } \\
(\mathbf{k N})\end{array}$} & \multicolumn{2}{|c|}{$\begin{array}{c}\text { Area of shear } \\
\text { reinforcement } \\
\quad\left(\mathrm{mm}^{2}\right)\end{array}$} & \multirow{2}{*}{$\begin{array}{c}\text { Variation in } \\
\text { failure loads of } \\
\text { CFP beams } \\
\text { with respect to AC } \\
\text { beams }\end{array}$} & \multirow{2}{*}{$\begin{array}{c}\text { Reduction in } \\
\text { shear reinforcement } \\
\text { in CFP Beams }\end{array}$} \\
\hline & $\begin{array}{c}\text { CFP } \\
\text { beams }\end{array}$ & $\underset{\text { beams }}{\text { ACI }}$ & $\begin{array}{c}\text { CFP } \\
\text { beams }\end{array}$ & $\underset{\text { beams }}{\text { ACI }}$ & $\begin{array}{c}\text { CFP } \\
\text { beams }\end{array}$ & $\begin{array}{c}\text { ACI } \\
\text { beams }\end{array}$ & & \\
\hline 4.44 & 43.1 & 42.72 & 55.6 & 49.7 & 339.43 & 1244.6 & $11.87 \%$ & $73 \%$ \\
\hline 3.5 & 51.68 & 52.54 & 59.9 & 64.3 & 339.43 & 1018.3 & $-6.84 \%$ & $66.67 \%$ \\
\hline 2.6 & 72.2 & 72.98 & 81.0 & 83.8 & 438.43 & 792 & $-3.34 \%$ & $46.64 \%$ \\
\hline 1.7 & 110.4 & 112.14 & 120.5 & 145.9 & 664.7 & 1018.3 & $-17.41 \%$ & $34.7 \%$ \\
\hline
\end{tabular}

\section{Conclusion}

In this investigation, shear resistance of concrete was better predicted by CFP concept as compared to ACI code approach. The experimental failure loads attained by the beams designed and detailed by both approaches were found comparable to the predicted failure loads. Moreover, CFP model demonstrates the ability to predict theoretical loads with sufficient accuracy and much lesser shear reinforcement of the order of $55 \%$ on an average; however, it fall short of attaining the desired flexural failure mode, except for a/d ratio 4.44 .

\section{References}

1. ACI 318M-08., American Concrete Institute, U.S.A, (2008)

2. M. D. Brown, O. Bayrak, J. O. Jirsa, ACI Struct. J., 103, (2006)

3. M. P. Collins, E.C. Bentz, E. G. Sherwood, ACI Struct. J. 105, (2008)

4. M. D. Kotsovos, ACI Struct. J, 85, (1988)

5. M. D. Kotsovos, M. N. Pavlovic, (Thomas Telford, London, 1999)

6. G. N. J. Kani, ACI J. Proceeding, 61, (1964) 